\title{
Memory Culture as the Main Priority of the Modern Education Process
}

\author{
Vladimir Kirik \\ Southern Federal University \\ Rostov-on-Don, Russia \\ E-mail:V.Kirik@gmail.ru
}

\author{
Tatiana Leshkevich \\ Southern Federal University \\ Rostov-on-Don, Russia \\ E-mail: Leshkevicht@mail.ru
}

\author{
Anna Motozhanets \\ Southern Federal University \\ Rostov-on-Don, Russia \\ E-mail: annamt@bk.ru
}

\begin{abstract}
The article considers the phenomenon of memory culture and its role in translating values within the education process. By analyzing the concept of memory culture, the authors reveal its functions, among which axiological, communicative, and moral functions appear to be the most significant. The purpose of the article is to study the concept of memory culture in the context of the education process and the need for an adequate representation of historical reality. The article dwells on three aspects of the issue. First, the phenomenon of collective memory is viewed in relation to psychological features of memory. Second, attention is given to a relatively new discipline in memory studies, memory policy, which may involve considering institutional orders for altering configurations of historical past and manipulating historical memory. Third, the article analyses various connotations of the memory concept, which include its mythological personification, space, and energy semantics. Theoretical basis of the research include works by Russian and foreign scholars: S. Rubinstein, A Luria, M. Halbwachs, P. Nora, P. Hutton, F. Yates, and P. Ricoeur. Methodological strategy relies on an interdisciplinary approach, which draws insights from both natural and social sciences and integrates those insights in a cooperative way. The dialectic method is of particular importance as it takes account of contradictions of the process of shaping memory culture. The study also relies on methodological principles of objectification and deobjectification as they demonstrate the relation between the perception of a past event and social context. The article concludes that memory culture provides an integrative base for shaping a person's value system in the process of education. Furthermore, memory culture appears to be dependent on both the priorities of the epoch and a subject of historical memory. Finally, autopoietic potential of memory underlies its innovative potential. With the increasing role of mass media in the contemporary world, studying the process of shaping historical memory is extremely relevant for the educational domain.
\end{abstract}

Keywords-memory culture; collective memory; nonautonomous; subject of memory

\section{INTRODUCTION}

Memory is the basic element of human life and its senseforming component. It provides for self-identification and preservation of value systems. The lessons of the past remain relevant for the present and the future by virtue of collective and social memory. That is why memory culture is of great importance both in the education process and personal life. Memory stores and revives facts and events from the past, transmitting the past to the present. It is memory that allows access to traditions, being responsible for their continuity or "death". In the contemporary world, historic memory is often buried in oblivion or subject to misinterpretations. Hence, shaping memory culture appears to be an essential goal of education. Memory culture is vitally important for the preservation of genuinely humane values, which makes it closely related to collective memory. The concepts of virtues and vices, heroic deeds, and historical disasters have always been essential symbols of memory and the basis for moral development of future generations

Good memory is critically important at all times and in any sphere. At the same time, the interrelation between the past and the present is far from simple. According to the dialectic approach, the present contains the past. However, the phenomenon of emergence testifies to the fact that the present also contains the new which did not exist in the past. The essence of progressive development consists in improving the past states and the emergence of new quality entities. The epoch and existence itself are manifested through historical and national, individual and collective memories. Memory culture should be based on the orderly presentation of historical facts and evidence. The current generation in its turn must necessarily take account of memory culture, which embraces all areas of everyday life, and professional and institutional spheres including the whole spectrum of human interactions. 


\section{CONCEPTUAL GROUNDING FOR StUdying MEMORY CULTURE}

In the context of social-humanitarian studies, memory is defined as the inner domain of experiencing values and nonreflexive connections with traditions. Memory culture rests upon actual historical events and collective memory. The phenomenon of memory culture can be defined through the correlation between real history and its reproduction in memory by means of written and aural traditions, historical documents, narration, and fiction. Memory culture relies on communicative, axiological, and moral functions. The communicative function is responsible for reproducing semantic connections between the past, the present, and the future. It is also responsible for the objective historical content free of subjective interpretations. At the same time, it is the communicative function that serves as the means of manipulation and speculations on the meaning of the past [1]. The axiological function is aimed at the assessment of current situations and reflects the degree to which an individual is involved in current events, which makes it an essential component of memory culture. It reveals the intensity of emotions and various attitudes attached to the meaning of current events which are important for an individual and the whole of humanity. The moral function of memory culture is connected with the process of elaborating a quality life path and learning lessons of the past, which has a universal humanitarian meaning. This function reveals the energy of an individual's goal-setting and aims at asserting the ideals of goodness, kindness and beauty. It is the moral dimension of memory culture that reflects the tensions of the modern epoch.

An established French scholar and a specialist in historic memory, P. Nora, studied the "deep roots" of collective memory. He tried to find the answer to the question of whether collective memory can be acquired. Collective memory is based on both documents and oral tradition. However, historical documents tend to represent the past in a "coded" way, and thus lack vividness of living memory. Oral tradition is open to multiple interpretations, which may lead to sematic and psychomental layerings that often distort the meaning of actual historical facts. At the same time, memory stores a semantic content that goes far beyond documented information. Memory is characterized by retrospective reflection which is fueled by the energy of emotions and feelings.

The nature and driving force of collective memory was studied in the works by M. Halbwachs, dating back to the period between the two World Wars. Relying on a sociocultural approach, the author claimed that the only way for memory to stand the test of time is to build on social context. Individual images of the past are very fragile and cannot last long; they can only be remembered when they become a part of conceptual structures defined by a particular community. If they are not systematically maintained by the community, individual memories tend to vanish without leaving a trace. This is how individual memories enter a social dimension, according to the author.
M. Halbwachs concluded that individual memories had to be positioned within the "social framework" (cadressociaux). In fact, individual memories appear to be a complex phenomenon comprising personal reminiscences intertwined with the understanding of the past shared by the community. Thus, M. Halbwachs' theory shows that collective memory regularly undergoes revisions by means of commemorative practices to make it serve the objectives of the present [2]. That is why commemorative practices, which illustrate the cult of individuality, can be viewed as a separate subject [3].

Scholars believe that memory safeguards a person's selfidentity, being a guide in the world of emotions. For instance, a Russian scholar, S. Rubinstein, states that, without memory, we would be "creatures of the moment"; our past would be closed to the present, while our present would gradually fall into oblivion [4]. Preserving memory means extending life beyond its biological sense.

According to the French scholar P. Ricoeur, memory is situated at the point of intersection of semantics with pragmatics [5]. Thus, it contains meaningful orientations which are closely connected with the needs and requirements of the present. Unfortunately, one cannot fail to see that in the context of a contemporary consumerist society (which is aimed at maximizing profit), the pragmatic interest tends to prevail over humanitarian values and changes the value system dramatically.

The research shows that the process of shaping memory culture cannot be free of contradictions. On the one hand, they are connected with imposed clichés and misconceptions; on the other hand, they are connected with the gaps in individual perceptions of the past and family memories. It is understood that memory should be "true to the past", but the problem is that the past is not properly reflected in the present. By getting in touch with the past, memory contains a challenge of reviving something which has forever disappeared. That is why the art of memory has become a popular issue in the debates around the phenomenon of memory [6]. Historically, the art of memory was represented by mnemonics which were quite popular in rhetoric. But the most important achievement consisted in understanding that mnemonics revealed the subordination of memory to a particular structural order assigned by the subject of memory. It is the subject of memory which chooses the configuration of events and assessments, thus defining the authenticity and identity of historic memory.

\section{Methodological StRATEGy OF THE RESEARCH}

If viewed as a mental process, memory appears to be a complicated phenomenon of a non-autonomous nature which is deeply rooted in evolution. From a neurophysiological standpoint, the storage capacity of memory, the ability to perceive and process complex signals from the environment, is proportional to the amount of nerve cells involved in the process. That is why an interdisciplinary approach to studying memory is viewed as the most effective methodological strategy. An interdisciplinary approach, which includes the data from the physiology of higher 
nervous activity, neuropsychology, biochemistry, and social and humanitarian sciences, can broaden the scope of studies into this highly complex phenomenon. A well-known psychologist, A. Luria, claimed memory to be a complex functional system which is dynamic, evolving over time, hierarchically organized, and can split into energy potential links [7].

Being an integrating base for the structural elements of consciousness, memory is closely connected with the cerebral substratum. Thus, a cognitive approach, as well as utilizing the principle of unity of consciousness and activity, appears to be effective in memory studies. A pragmatic approach is also essential insofar as the productive capacity of memory includes mechanisms that bring together information of the past event and its relevance to the present moment. The pragmatic approach forms the basis of the "memory policies" responsible for a particular worldview. Numerous memory policies, together with their relevant attributes, tend to regulate the past and influence the present and the future. Here, the methodological principles of objectification and deobjectification (close to the method of reconstruction) play a significant role as they demonstrate the relation between the perception of a past event and social context.

A living memory is believed to be a combination of repetition and recollection. In the course of numerous repetitions of individual memories, the distinctive features gradually disappear. They are "blended" into stereotyped images, which shape collective memory. Thus, what is remembered from a repetitive experience is a product of reducing individual memories to an idealised or stereotyped image (imago). There arises a dialectic interrelation between collective and individual memory, according to which the repetition of individual and unique experience gives rise to a stereotype reflecting the collective matrix. Another effect of dialectic interrelations consists in the following: a traditional stereotype of collective memory influences the individual's worldview, forcing individual memory to revive past events that let a person fit into the existing social frame. All the above factors lead to the conclusion that the structure of collective memory sets a specific model within which individual memories have to fit in the existing framework.

Thus, the methodological strategy based on an interdisciplinary approach and the dialectics of the individual and the collective testifies to the "non-autonomous" nature of the phenomenon. In turn, the "non-autonomous" nature of memory indicates a close connection between memory and inner immanent processes, namely, feelings, emotions, reflections, and perceptions. Memory appears to be an overarching process that ensures continuity and interaction of all mental functions. Moreover, the "non-autonomous" nature of memory reveals its dependence on external ways of objectification and ideological context, which is connected with constructing a certain version of social memory. Finally, the "non-autonomous" nature of memory derives from its reliance on the subject of the memory, namely the community that aims at either nurturing memories of the past or committing them to oblivion.

\section{CONNOTATIONS OF MEMORY IN THE HISTORY OF HUMAN THOUGHT}

A factor of great significance to the phenomenon of memory is reflected in the ancient sources such as Greek mythology where Mnemosyne is both a personification and a goddess of memory. Those who drank from the spring of Mnemosyne were said to gain knowledge. As the personification of memory, Mnemosyne was the mother of the nine Muses, including the muse of invention. Thus, in mythology, knowledge and invention were seen as the "children" of memory. In the Theogony, Hesiod emphasized the significance of memory, claiming that Mnemosyne was the reason for everything [8]. In some of his dialogues, Plato mentioned anamnesis (recollection) and emphasized the meaning of memory for "bearing spiritual fruits". He also touched upon the problem of the interrelation between traces of memory and previous emotional experience. Aristotle saw memory as having an internal image that represents past experience. Aristotle's conclusion that memory provides for the linking of times is still relevant. Medieval philosophy shifts the emphasis to inner memory. St. Augustine considers inner memory (memoria interior) to be the foundation of thinking in general [9]. In modern times, Hobbes states that we transform our memories into a foresight of the things to come [10].

It should be emphasized that spatial connotations are used to describe memory very often. For instance, "memory storage" or "repository of memories" imply that memory is viewed as the foundation of the inner world, a resource of which one can fall back on at any time. The processes of memorizing, remembering, and reproducing, activated by motivation and goal-setting, fill up this storage with various intensity.

A hundred years later, H. Bergson reached a fundamental conclusion that memory defines the relation between spirit and matter and serves as their intersection point [11]. Bergson also states that, when absorbed by memory, perceptions become a motivating thought that inspires action. Hence, the call for personification and metaphorization of memory. Thus, autopoietic potential of memory provides for the continuity of the past in the present and underlies its innovative potential. Since the trajectory of the future largely depends on our experience, which is stored in our memory, the procedural nature of memory in terms of repetitions and memorizing is of particular importance.

"Memory trace" is another metaphor which indicates that the mechanisms of memory serve as the foundation for the present existence and prospects for the future. Moreover, memory can process and filter its content, highlighting some and suppressing others. This is how memory "makes its contribution" to our immediate perceptions and leaves its "trace". The past depends on the way of its representation. There is also a metaphor of "the theatre of memories" which illustrates the fact that the same event can be subject to multiple interpretations. Memory is capable of reviving the past experience and deserves its own space. That is why the so-called "places of remembrance" carry both a symbolic and actual meaning in people's lives. 
Connotations of the notion of memory are numerous: long-term and short-term memory, memory depth, memory "like a sieve", memory overload, to "bear in memory", "interrogate memory", "extract from memory", something or somebody may "live on in the memory", et al. Memory "disturbances" are often mentioned both seriously and jokingly. At the same time, a metaphorical expression "the force of memory" emphasizes its energy potential. Referring to a weakening public memory means social malfunction, the rise in social entropy, and breakdowns in the process of transferring values and traditions.

The "journey into the mind", interiorizing historical memory, are vitally important as these processes are part of personality development and self-identification [12]. It is memory that makes intellectual reflection possible. It is worth mentioning that memories and reminiscence aimed at self-justification testify to the depletion of development resources. Historical self-justification is rightly considered to be a sign of setback and stagnation.

\section{CONCLUSION}

The study into the phenomenon of "memory culture" reveals that it is deeply rooted in actual history, reflected in oral tradition, and embodied in symbolism, visual images, and written documents. Memory culture can be viewed as a fundamental mechanism of shaping meanings and values for the present and future existence.

Collective memory is in constant need of social support; it appears to be a retrospection connected with the present requirements. Throughout the history of mankind, there have been many examples of how memory of the past was lost. Memory culture is a good way to learn from the lessons of the past. Filled with the energy of emotions, memory culture is a powerful consolidation mechanism. Memory culture cannot be reduced to rationalization and ideologization of the past. Nor can it be narrowed down to the so-called presentism, which is aimed at the dictatorship of the present moment. The productive capacity of memory culture aims at maintaining an integral vision of current events. Memory culture is in possession of mechanisms that integrate the inward and the outward, or a past event and its meaning for the future, which may be particularly relevant for the educational process.

The process of shaping memory culture is full of contradictions. Memory is dependent upon a particular structural order, which is set by its subjects and determined by the priorities of the epoch. The quality of historical memory, its objectivity and identity, depend largely on the configuration of events and assessment chosen by the subject of the memory. By learning from the lessons of the past, memory culture aims at shaping value priorities and semantic meanings of the present, which makes it an effective management tool with regard to the present and the future. Memory culture strives to preserve the world heritage and formulate genuine priorities of human existence. The tendency of "post-national" memory culture should be viewed as a challenge, which undermines the idea of selfidentity and testifies to its course deviation. At the same time, memory culture may serve as a "catalogue" or a "draft project" that is meant to pass on the baton to the next generation.

\section{REFERENCES}

[1] T. Leshkevich, "Communicative Practices in their Semantic Orientations on Algorithms of Successful Interactions" in Proceedings of 4th International Conference on Education, Language, Art and Intercultural Communication (ICELAIC 2017), 2017, pp. 374-377.

[2] M. Halbwachs, Social Classes and Morphology, M., SPb, IES-Alteya, 2000.

[3] P. Hutton, History as the Art of Memory http://www.gumer.info/bibliotek_Buks/History/hatt/01.php

[4] S. Rubinstein, General Psychology, SPb, Piter, 2000.

[5] P. Ricoeur, Memory, History, Forgetting, M., Izdatelstvo Gumanitarnoy Literatury, 2004, pp. 25-43.

[6] F. Yates, The Art of Memory, SPb, Universitetskaya Kniga, 1997.

[7] Luria, Neuropsychology of Memory, 4th ed., M., 2005, P. 28.

[8] Hesiod, "Works and Days, Theogony" in Hellenic Poets, Library of Ancient Literature, translated by V. Veresajev, M., 1963.

[9] T. Litvin, "Temporality as a property of the past in St. Augustine's doctrine of time" in Topos № 1 (21), 2009, pp. 5-12.

[10] T. Hobbes, Works, vol. 2, M., Mysl Publ., 1991.

[11] A. Bergson, "Matter and Memory" in A. Bergson, Collected Works, vol.1, M., Moskovskij klub Publ., 1992.

[12] T. Leshkevich, "The Problem of Quality Unpacking the Meanings of Existence” in Nauchnaya Mysl Kavkaza, №4, 2014, pp. 14-22. 